\title{
Human serum albumin-mediated apoptin delivery suppresses breast cancer cell growth in vitro and in vivo
}

\author{
FANG WU ${ }^{1 *}$, YIZHI LIU ${ }^{2 *},{\text { JIAN } \text { LI }^{3 *}, \text { LEI HOU }}^{4}$, FUXI LEI $^{1}$, \\ SHANGKE HUANG ${ }^{1}$, LU FENG $^{1}$ and XINHAN ZHAO ${ }^{1}$ \\ ${ }^{1}$ Department of Medical Oncology, The First Affiliated Hospital of Xi'an Jiaotong University; \\ ${ }^{2}$ Department of Medical Oncology, Shaanxi Provincial Tumor Hospital, Xi'an, Shaanxi 710061; \\ Departments of ${ }^{3}$ Medical Imaging and ${ }^{4}$ Medical Oncology, Shaanxi Provincial People's Hospital, \\ Xi'an, Shaanxi 710068, P.R. China
}

Received July 12, 2015; Accepted August 19, 2016

DOI: $10.3892 / \mathrm{ol} .2016 .5470$

\begin{abstract}
Gene therapy is one of the most promising potential therapeutic strategies for many types of cancer. Cell apoptosis is an active, programmed physiological process of the body, and its disruption has been closely associated with the occurrence of tumor development. Apoptin is known to induce tumor cell apoptosis. In the present study, the MCF-7 breast cancer cell line was transfected with a human serum albumin (HSA) and apoptin expressing plasmid [HSA-polyethylenimine (PEI)-pcDNA-Apoptin]. Reverse transcription-quantitative polymerase chain reaction and western blotting were performed to detect the expression of apoptin in the transfected MCF-7 cells, while MTT assays and flow cytometry were conducted to detect cell viability and apoptosis. Furthermore, hematoxylin and eosin staining was used to observe the morphology of xenografts from mice injected with MCF-7 cells. It was demonstrated that the HSA-PEI-pcDNA-Apoptin expression plasmid resulted in the upregulation of apoptin in MCF-7 cells, and efficiently suppressed breast tumor growth in vivo. These findings indicated that the use of HSA as an apoptin expression vector has potential therapeutic benefits for cancer and confirms the requirement for the further evaluation of apoptin in clinical trials.
\end{abstract}

\section{Introduction}

Breast cancer is the most common cancer in women, and its incidence shows an increasing trend globally (1-3). Annually,

Correspondence to: Professor Xinhan Zhao, Department of Medical Oncology, The First Affiliated Hospital of Xi'an Jiaotong University, 227 Yanta West Road, Xi'an, Shaanxi 710061, P.R. China E-mail: zhaoxinhanprof@163.com

\section{${ }^{*}$ Contributed equally}

Key words: gene therapy, human serum albumin, apoptin, breast cancer, antitumor effects $\sim 1,400,000$ women are diagnosed with breast cancer worldwide, of which there are 500,000 mortalities. The incidence of breast cancer in China has also increased rapidly, and is a huge threat to the health of Chinese women $(4,5)$. At present, the treatment of breast cancer predominantly involves surgery combined with chemotherapy, endocrine therapy, targeted therapy or immunotherapy, which has shown good curative effects; however, the current treatment strategy has not shown good therapeutic effects for all patients.

Gene therapy is the most promising potential treatment option for cancer, and is currently undergoing rapid development. Selecting appropriate therapeutic genes is the first stage in the development of gene therapy. Various genes have been investigated for their potential use in gene therapy, including genes that allow 'immortalization' of cells, which is a prerequisite for tumor formation, and genes that promote or induce tumor cell apoptosis (6). Apoptin, which is derived from the chicken anemia virus (CAV), is a highly conservative protein that has no homology with other animal or viral sequences (7). Due to its ability to selectively induce apoptosis in a large panel of human malignant cells, without affecting normal cells, it has emerged as an important potential agent for cancer gene therapy (8).

An efficient gene delivery method is crucial for the implementation of gene therapy. Nonviral gene delivery systems, which involve using natural or synthetic proteins as delivery tools, have become increasingly popular due to their advantages, including safety, stability and relative cheapness (9). Human serum albumin (HSA) is the most abundant protein in serum, and is the main driving force of the circulatory system. HSA is also an important source of nutrition for the cells of the body. As tumor development requires a large volume of nutrients, HSA has been shown to accumulate in solid tumors (10). Rhaese et al (11) successfully constructed a HSA-DNA complex, and assessments of its stability, cytotoxicity, nuclease resistance and transfection and expression efficiency demonstrated that HSA may be an ideal gene delivery tool.

The present study developed a gene therapy approach incorporating the delivery of the cancer-specific cytotoxic protein, apoptin, with HSA as a vector for the treatment of breast cancer. The HSA-polyethylenimine (PEI)-pcDNA-Apoptin construct was transfected into the MCF-7 breast cancer cell line, and 
the in vitro and in vivo effects on MCF-7 cell viability and apoptosis were determined. When systemically delivered into mice, the HSA-PEI-pcDNA-Apoptin construct was capable of inducing apoptosis and causing significant tumor regression, in the absence of damage to normal tissues.

\section{Materials and methods}

Cells and reagents. The MCF-7 breast cancer cell line was obtained from the Type Culture Collection of the Chinese Academy of Sciences (Shanghai, China). MCF-7 cells were cultured in RPMI-1640 medium supplemented with $10 \%$ fetal bovine serum, $100 \mathrm{U} / \mathrm{ml}$ penicillin and $100 \mu \mathrm{g} / \mathrm{ml}$ streptomycin (complete medium; Invitrogen; Thermo Fisher Scientific, Inc., Waltham, MA, USA) at $37^{\circ} \mathrm{C}$ in $5 \% \mathrm{CO}_{2}$. HSA and PEI were purchased from Sigma-Aldrich; Merck Millipore (Darmstadt, Germany). The enhanced green fluorescent protein (EGFP)-N1 plasmid (pEGFP-N1) was a gift from Professor Xinhan Zhao of Xi'an Jiaotong University (Xi'an, China). The study was approved by the Ethics Committe of Xi'an Jiaotong University.

Construction of the expression vector. The expression vectors containing apoptin or EGFP were generated under the control of the cytomegalovirus promoter. The apoptin gene was synthesized by Shanghai GenePharma Co., Ltd. (Shanghai, China) based on sequences in GenBank (accession no. Ay171617), and amplified by polymerase chain reaction (PCR) using Taq DNA polymerase (Sigma-Aldrich; Merck Millipore). The primers were: Sense, 5'-ACGAAT TCCGATGAACGCTCTCCAAGAAGATACTC-3' and antisense, 5'-CAGGATCCGTFGACAGTCTFATACACCTTC TTGCG-3'. The terminals of the primers were used to introduce the Eco RI and Xba I excision sites. PCR was performed with an initial denaturation step at $94^{\circ} \mathrm{C}$ for $5 \mathrm{~min}$, followed by 35 cycles of denaturation at $94^{\circ} \mathrm{C}$ for $30 \mathrm{sec}$, annealing at $56^{\circ} \mathrm{C}$ for $45 \mathrm{sec}$ and extension at $72^{\circ} \mathrm{C}$ for $45 \mathrm{sec}$. A final extension step at $72^{\circ} \mathrm{C}$ for 10 min was performed. The PCR products were separated by agarose gel electrophoresis and the bands were purified from the gels. The PCR fragments were cloned into pEGFP-N1 using the T4 DNA ligase (Sigma-Aldrich; Merck Millipore). Subsequently, the insert site was released from pEGFP-N1 by digestion with Eco RI and Xba I restriction enzymes (Sigma-Aldrich; Merck Millipore), and PCR fragments were cloned into pEGFP-N1 using the T4 DNA ligase; the complex was termed pEGFP-N1-Apoptin, which was amplified in bacterial cells ( $E$. coli DH5 $\alpha$; Takara Bio, Inc., Otsu, Japan). The cells were transfected with pEGFP-N1-Apoptin as follows: Following thawing of competent cells, $2 \mu \mathrm{l}$ pEGFP-N1-Apoptin was added to $100 \mu \mathrm{l}$ competent cells and incubated on ice for $30 \mathrm{~min}$. This was followed by incubation in water for $45-60 \mathrm{sec}$ at $42^{\circ} \mathrm{C}$, then incubation on ice for $2 \mathrm{~min}$, vortexing for $1 \mathrm{~h}$ at $37^{\circ} \mathrm{C}$ after added $900 \mu \mathrm{l}$ SOC media. Finally, $100 \mu \mathrm{l}$ bacteria liquid was added to the Luria-Bertani (LB) media, which contained $50 \mu \mathrm{g} / \mathrm{ml}$ kanamycin, and was incubated for $12-16 \mathrm{~h}$ at $37^{\circ} \mathrm{C}$ so that bacterial colonies would appear and select for positive clones. The pcDNA-EGFP vector was constructed by excising EGFP from the pEGFP-N1 plasmid using Eco RI/Xba I restriction enzymes and sub-cloning into the Eco RI and Xba I sites of pcDNA3.1 (Sigma-Aldrich; Merck Millipore).
The pcDNA-Apoptin vector was constructed by subcloning the apoptin fragment from pEGFP-Apoptin into pcDNA3.1.

Construction of recombinant HSA-PEI-pcDNA-Apoptin. HSA (10 mg) was dissolved in $0.05 \mathrm{~mol} / 1$ 2-(N-Morpholino) ethanesulfonic acid (MES) and $0.05 \mathrm{~mol} / 1 \mathrm{NaCl}(\mathrm{MES} / \mathrm{NaCl})$ buffer solution ( $\mathrm{pH}$ 4). Subsequently, $300 \mathrm{mg}$ 1-ethyl-3-(3-dimethyllaminopropyl)carbodiimide hydrochloride and $0.06 \mathrm{~mol} / \mathrm{l} \mathrm{N}$-hydroxysuccinimide (NHS) were dissolved in $\mathrm{MES} / \mathrm{NaCl}$ buffer to form an NHS-HSA ester. PEI (10 mg) was reacted with NHS-HSA solution at room temperature, and stirred for $20 \mathrm{~h}$ using a magnetic stirring apparatus. The HiTrap SP FF ion exchange column reagent kit (GE Healthcare Life Sciences, Shanghai, China) was used to purify the synthesized HSA-PEI according to the manufacturer's protocols. Finally, $10 \mu \mathrm{g}$ HSA-PEI and $10 \mu \mathrm{g}$ pcDNA-Apoptin or pcDNA were dissolved in $100 \mathrm{ml}$ pure water. The recombinant HSA-PEI-pcDNA-Apoptin and HSA-PEI-pcDNA constructs were used for the following experiments. In order to identify the recombinant plasmid, the recombinant plasmid was digested using EcoRI and $X b a I$ restriction enzymes, and the products were separated by $1 \%$ agarose gel electrophoresis.

Cell transfection. MCF-7 cells $\left(2 \times 10^{5}\right)$ were cultured in 24-well culture plates. Upon reaching the logarithmic growth phase, various concentrations of HSA-PEI-pcDNA-Apoptin $(0,0.1$, $0.25,0.5$ or $1.0 \mathrm{mg} / \mathrm{ml}$ ) were added to the cells. After $24 \mathrm{~h}$, the cells were stable, and were permeabilized and washed with phosphate-buffered saline (PBS), after which apoptin expression was examined under a fluorescence microscope.

Cell viability assay. The MTT assay (Sigma-Aldrich; Merck Millipore) was performed to detect cell viability following the transfection of MCF-7 cells with the HSA-PEI-pcDNA-Apoptin construct. MCF-7 cells were cultured in 96 -well plates at a density of $4 \times 10^{4} / \mathrm{ml}(200 \mu \mathrm{l}$ per well) for $24 \mathrm{~h}$ at $37^{\circ} \mathrm{C}$. Each plate was divided into three groups, including the HSA-PEI-pcDNA-Apoptin group, the HSA-PEI-pcDNA group and the blank control group. Subsequently, HSA-PEI-pcDNA-Apoptin, HSA-PEI-pcDNA and $0.9 \% \mathrm{NaCl}$ were added to the appropriate wells and, after $24 \mathrm{~h}$, $20 \mu \mathrm{l}$ MTT $(5 \mathrm{mg} / \mathrm{ml})$ was added for $4 \mathrm{~h}$ at $37^{\circ} \mathrm{C}$. The culture media was removed and the crystals were dissolved by addition of $150 \mu \mathrm{l}$ dimethylsulfoxide per well, and oscillating for $15 \mathrm{~min}$ at room temperature. The absorbance of the reaction solution was measured at $490 \mathrm{~nm}$ using a microplate reader (Multiskan FC; Thermo Fisher Scientific, Inc.). The inhibition rate of cell growth was calculated as follows: Inhibition rate $(\%)=(1-$ absorbance of experimental group / absorbance of control group) x 100 .

Flow cytometric analysis. The effect of HSA-PEI-pcDNA-Apoptin on cell apoptosis was determined by flow cytometry using the Annexin V-phycoerythrin (PE)/7-aminoactinomycin D (7-AAD) Apoptosis kit (Genechem, Co., Ltd., Shanghai, China), according to the manufacturer's protocol. Briefly, MCF-7 cells were rinsed twice using PBS, digested with trypsin and centrifuged at $400 \mathrm{x} g$ for $5 \mathrm{~min}$. The cells were incubated with $50 \mu \mathrm{l}$ Binding Buffer and $5 \mu 1$ 7-AAD for 5-15 min in the dark at room temperature. Subsequently, 
$450 \mu \mathrm{l}$ Binding Buffer and $1 \mu \mathrm{l}$ Annexin V-PE were added to the cells for 5-15 min. The samples were analyzed using the BD FACSAria $^{\mathrm{TM}}$ III Cell Sorter (BD Biosciences, San Jose, CA, USA), and the data were analyzed using FlowJo 7.6.1 software (FlowJo, LLC, Ashland, OR, USA).

Semi-quantitative reverse transcription $(R T)-P C R$. To detect the mRNA expression of apoptin in MCF-7 cells, total RNA was extracted using TRIzol reagent (Thermo Fisher Scientific, Inc.), according to the manufacturer's protocol. RT-PCR was performed using the OneStep RT-PCR kit (Thermo Fisher Scientific, Inc.) and the following manually designed PCR primers: Apoptin sense, 5'-CGGCCGGCGTGGGATGAA CGATCTCCAAGAAGATAC-3' and antisense, 5'-CAAGCT TCAGTCTTATACGCCTTCTTGCGGTTC-3'; and $\beta$-actin sense, 5'-TGACGGGGTCACCCACACTG-3' and antisense, 5'-TAGAAGCATTTGCGGTGGAC-3'. The PCR cycling conditions were as follows: 35 cycles of $94^{\circ} \mathrm{C}$ for $30 \mathrm{sec}, 56^{\circ} \mathrm{C}$ for $30 \mathrm{sec}$ and $72^{\circ} \mathrm{C}$ for $30 \mathrm{sec}$, followed by an extension step at $72^{\circ} \mathrm{C}$ for $10 \mathrm{~min}$. Subsequently, the PCR products were separated by $1.5 \%$ agarose gel electrophoresis, with $\beta$-actin as an internal marker. Images of the gel were captured, and the apoptin gene was analyzed, using the GeneGenius Bio Imaging system (Syngene, Frederick, MD, USA).

Western blot analysis. MCF-7 cells were washed three times with cooled PBS and lysed using radioimmunoprecipitation assay lysis buffer (Xi'an Heart Biotechnology, Co., Ltd., Xi'an, China) containing $2 \mathrm{mg} / \mathrm{ml}$ protease inhibitors for $30 \mathrm{~min}$. The lysates were then centrifuged at 25,000 x $g$ for $20 \mathrm{~min}$ at $4^{\circ} \mathrm{C}$, followed by boiling in loading buffer for $5 \mathrm{~min}$. Total protein concentrations were determined using a Bradford protein assay (Sigma-Aldrich; Merck Millipore), and $150 \mu \mathrm{g}$ protein samples were separated by $10 \%$ SDS-PAGE and transferred onto polyvinylidene difluoride membranes. The membranes were blocked using $5 \%(\mathrm{w} / \mathrm{v})$ skimmed milk powder (Inner Mongolia Yili Industrial Group, Co., Ltd., China) dissolved in Tris-buffered saline containing $0.1 \%$ Tween-20 (TBS-T) for $1 \mathrm{~h}$ at room temperature. The membranes were incubated with anti-apoptin (1:1,000 dilution; catalog no. ab193612; Abcam, Cambridge, MA, USA) and anti- $\beta$-actin (1:1,000 dilution; catalog no. sc-47778; Santa Cruz Biotechnology, Inc., Dallas, TX, USA) antibodies at $4^{\circ} \mathrm{C}$ overnight. After washing three times with TBS-T, the membranes were incubated with the goat anti-mouse IgG1-HRP (1:10,000 dilution; catalog no. sc-2060; Santa Cruz Biotechnology, Inc.) and goat anti-rabbit IgG-HRP (1:5,000 dilution; catalog no. sc-2030; Santa Cruz Biotechnology, Inc.) secondary antibodies for $2 \mathrm{~h}$ at room temperature. The membranes were then washed with TBS-T three times for $10 \mathrm{~min}$, then either applied with enhanced chemiluminescence reagents (Merck Millipore), according to the manufacturer's protocols, and exposed to X-ray film, or applied with DAB (from which brown staining was visualized). Autoradiogram signals were quantified using a gel densitometric scanning program. The relative expression of protein was determined from the optical density ratio of the corresponding protein bands, as quantified using Quantity One 4.6.2 software (Bio-Rad Laboratories, Inc., Hercules, CA, USA).

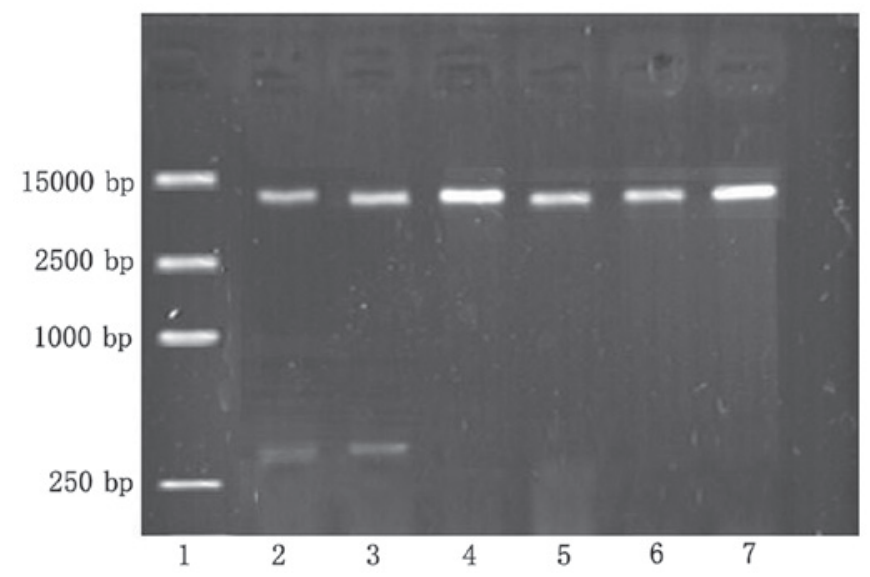

Figure 1. Successful establishment of the human serum albumin-polyethylenimine-pcDNA-Apoptin expression vector was confirmed by $1 \%$ agarose gel electrophoresis. Lane 1, DL15000 DNA marker. Lanes 2 and 3, pcDNA-Apoptin was digested by Eco RI and Xba I restriction enzymes, and produced two fragments: apoptin at $376 \mathrm{bp}$ and p-enhanced green fluorescent protein (EGFP)-N1 at 5,000 bp. Lanes 4 and 5, pEGFP-N1 was digested by Eco RI and Xba I restriction enzymes, and produced only one fragment at 5,000 bp. Lanes 6 and 7, the pEGFP-N1 plasmid.

Experiments on a nude mouse model in vivo. A total of $15 \mathrm{BALB} / \mathrm{c}$ nu/nu athymic nude female mice (4-5 weeks-of-age) were purchased from Shanghai Silaike Laboratory Animal Co., Ltd. (Shanghai, China). The mice were maintained at $\mathrm{Xi}$ 'an Jiaotong University in a sterile environment, with a temperature of $22-23^{\circ} \mathrm{C}$, relative humidity of $45-55 \%$, light/dark cycles of $12 / 12 \mathrm{~h}$, and food and water provided daily, in compliance with the Institutional Animal Care and Use Committee regulations. The mice were subcutaneously injected with $1 \times 10^{6}$ MCF-7 cells $(0.1 \mathrm{ml})$ into the left side of the second breast fat pad. When the tumors had reached $\sim 100 \mathrm{~mm}^{3}$ in volume, the mice were randomized into three groups, as follows: i) The HSA-PEI-pcDN-Apoptin $(0.5 \mathrm{mg} / \mathrm{ml})$ group; ii) the HSA-PEI-pcDNA $(0.5 \mathrm{mg} / \mathrm{ml})$ group; and iii) the saline (control) group. The mice were injected $(0.5 \mathrm{ml})$ into the tail vein with HSA-PEI-pcDN-Apoptin, HSA-PEI-pcDNA or saline once per day, and the tumor volumes were measured every 3 days. Tumor volumes were calculated using the equation: Tumor volume $\left(\mathrm{mm}^{3}\right)=$ length $\mathrm{x}$ width ${ }^{2} \mathrm{x} 0.5$. After 25 days, the mice were sacrificed by cervical dislocation. The liver, lungs, kidneys and tumor tissues were harvested, fixed in $4 \%$ paraformaldehyde solution and embedded in paraffin. The liver and lung paraffin sections were stained with hematoxylin and eosin (HE), and were independently evaluated by two pathologists. The tissue proteins were extracted for western blot assay.

The handling of animals was in accordance with the Animal Care Guidelines of Xi'an Jiaotong University of Medical Sciences Ethical Committee. All the experiments were performed to minimize the stress and pain experienced by the animals.

Statistical analysis. Statistical analyses were performed using SPSS 13.0 software for Windows (SPSS Inc., Chicago, IL, USA). Two-tailed Student's t-tests were used for comparisons between two groups. Data are expressed as the mean \pm standard deviation. $\mathrm{P}<0.05$ was considered to indicate a statistically significant difference. 
A
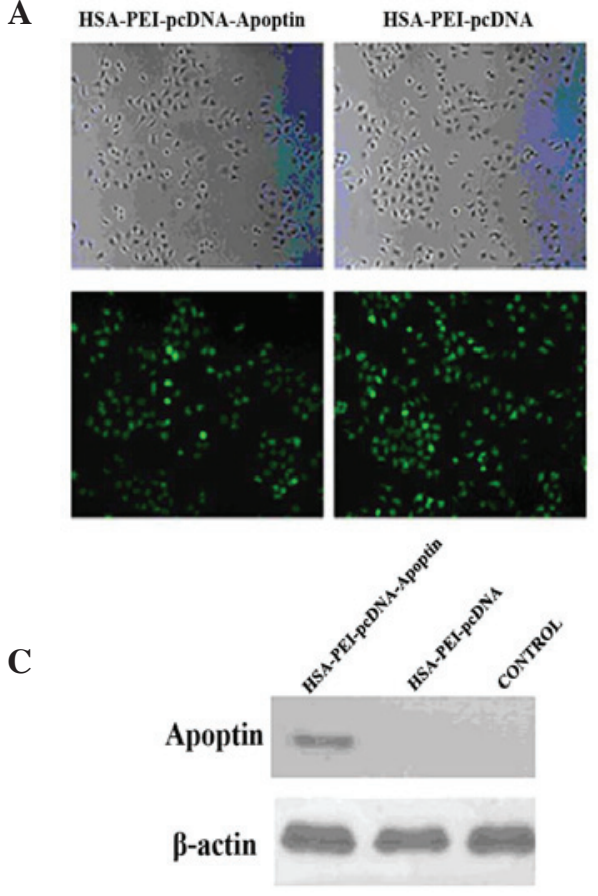

B
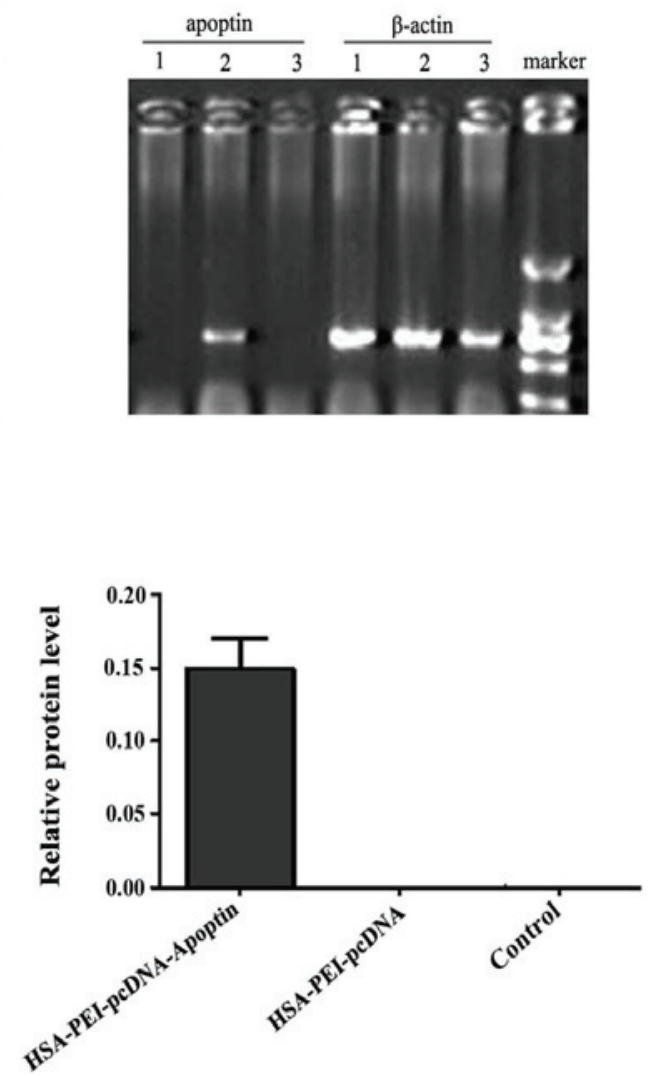

Figure 2. Expression of apoptin in MCF-7 cells transfected with HSA-PEI-pcDNA-Apoptin. (A) MCF-7 cells transfected with $0.5 \mathrm{mg} / \mathrm{ml}$ HSA-PEI-pcDNA-Apoptin and HSA-PEI-pcDNA were observed by fluorescence microscopy at $24 \mathrm{~h}$ following transfection (magnification, $\mathrm{x} 200$ ). (B) Reverse transcription-polymerase chain reaction (RT-PCR) analysis of apoptin and $\beta$-actin mRNA expression in MCF-7 cells transfected with HSA-PEI-pcDNA-Apoptin . (C) Western blot analysis of apoptin protein expression in MCF-7 cells transfected with HSA-PEI-pcDNA-Apoptin. The cells were harvested at $24 \mathrm{~h}$ after transfection for analysis of apoptin expression. Lane 1, HSA-PEI-pcDNA; lane 2, HSA-PEI-pcDNA-Apoptin; lane 3, blank control. HSA, human serum albumin; PEI, polyethylenimine.

\section{Results}

Successful establishment of the HSA-PEI-pcDNA-Apoptin expression plasmid. The recombinant plasmid was digested using Eco RI and Xba I restriction enzymes, and the products were separated by $1 \%$ agarose gel electrophoresis, which produced two fragments: Apoptin (376 bp) and pEGFP-N1 (5,000 bp) (Fig. 1). Sequencing by Sigma-Aldrich (Thermo Fisher Scientific, Inc.) demonstrated that the apoptin gene sequence of the recombinant plasmid was the same as the apoptin sequence in GenBank (accession no. Ay171617). The apoptin DNA and EGFP DNA sequences were shown to form a complete reading frame, without frameshift mutations, which conformed to the experimental design.

Apoptin expression in MCF-7 cells transfected with HSA-PEI-pcDNA-Apoptin. To determine whether HSA-PEI-pcDNA-Apoptin was successfully transfected into MCF-7 human breast cancer cells, the cells were transfected with various concentrations of HSA-PEI-pcDNA-Apoptin or HSA-PEI-pcDNA, and were observed by fluorescence microscopy after $24 \mathrm{~h}$. Approximately $90 \%$ of cells transfected with 0.5 or $1.0 \mathrm{mg} / \mathrm{ml}$ constructs showed positive green fluorescence staining (Fig. 2A). For economic reasons, $0.5 \mathrm{mg} / \mathrm{ml}$
HSA-PEI-pcDNA-Apoptin was used in the subsequent in vivo experiments. The mRNA and protein expression of apoptin in MCF-7 cells was confirmed by semi-quantitative RT-PCR and westernblotting.Apoptintranscripts were detected in MCF-7 cells at $24 \mathrm{~h}$ following transfection. Apoptin mRNA was only detected in MCF-7 cells transfected with HSA-PEI-pcDNA-Apoptin (Fig. 2B); $\beta$-actin was an internal marker (Fig. 2C). Western blot analysis confirmed that apoptin was only expressed in the MCF-7 cells transfected with HSA-PEI-pcDNA-Apoptin, and not in the HSA-PEI-pcDNA-transfected or blank control cells (Fig. 2D). These results suggest that the HSA-PEI-pcDNA-Apoptin construct can be transfected into breast cancer cells, resulting in the stable expression of apoptin.

HSA-PEI-pcDNA-Apoptin reduces the viability and induces the apoptosis of MCF-7 cells. To identify whether HSA-PEI-pcDNA-Apoptin was able to reduce the viability of MCF-7 cells, MCF-7 cells were transfected with HSA-PEI-pcDNA-Apoptin or HSA-PEI-pcDNA, or treated with saline (blank control), and MTT assays were performed to assess the cytotoxic effects. The cell viability of the HSA-PEI-pcDNA-Apoptin group was decreased by $14.3 \%$ following transfection with HSA-PEI-pcDNA-Apoptin, whereas the viability of the other two groups did not 

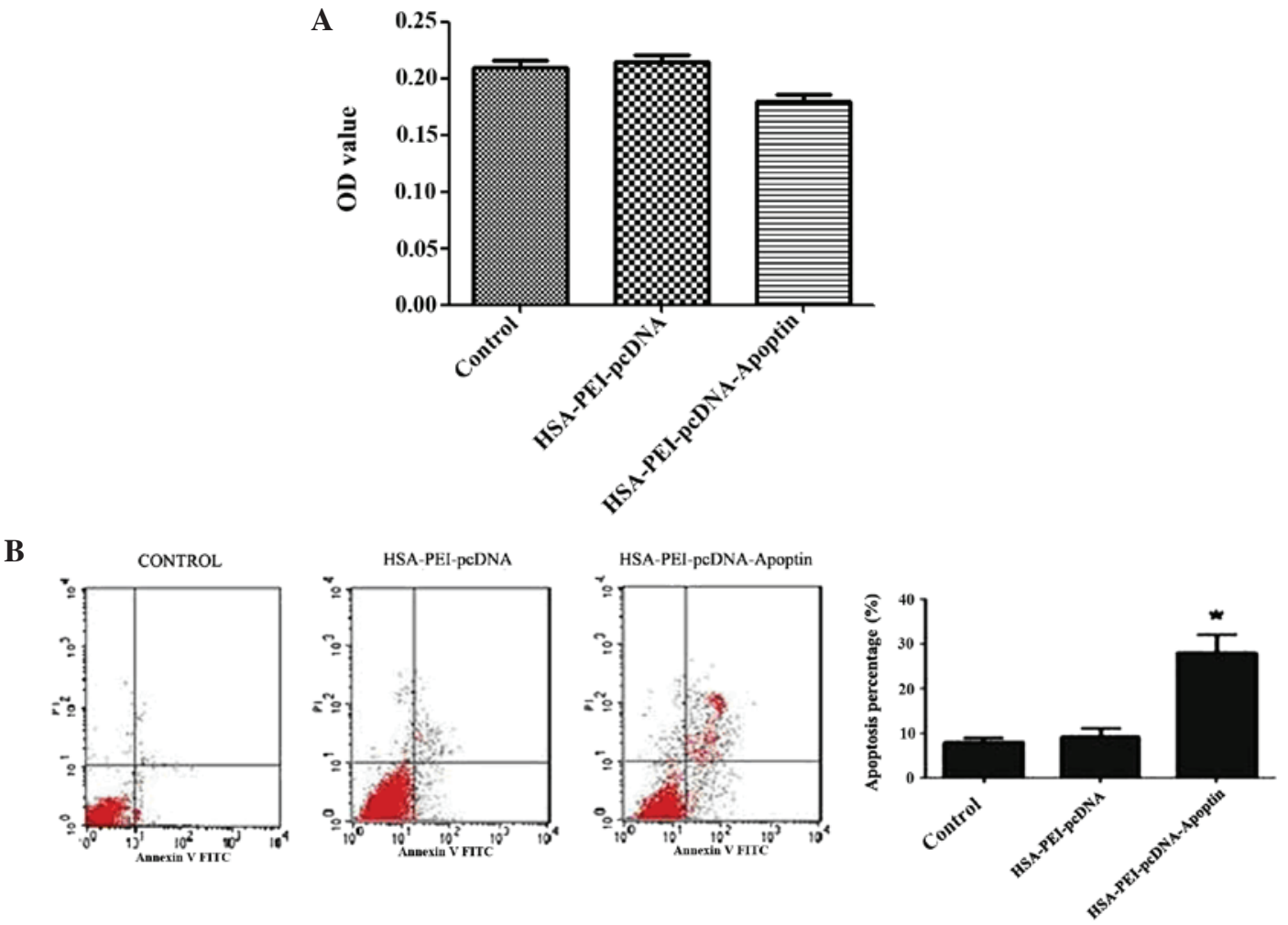

Figure 3. HSA-PEI-pcDNA-Apoptin reduces the viability and induces the apoptosis of MCF-7 cells. (A) MTT assays demonstrated that the viability of MCF-7 cells was reduced following transfection with the HSA-PEI-pcDNA-Apoptin expression vector. OD value of three groups. (B) Flow cytometric analysis indicated that MCF-7 cell apoptosis was significantly reduced following transfection with HSA-PEI-pcDNA-Apoptin. Data are presented as the mean \pm standard deviation of triplicate experiments. "P<0.05 vs. control. HSA, human serum albumin; PEI, polyethylenimine; OD optical density.

A

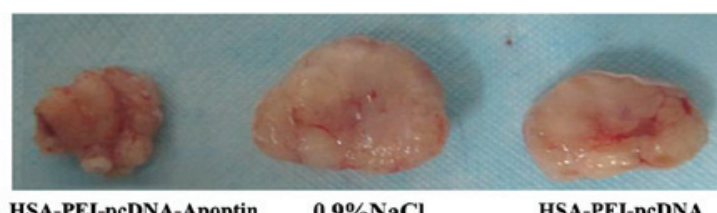

C

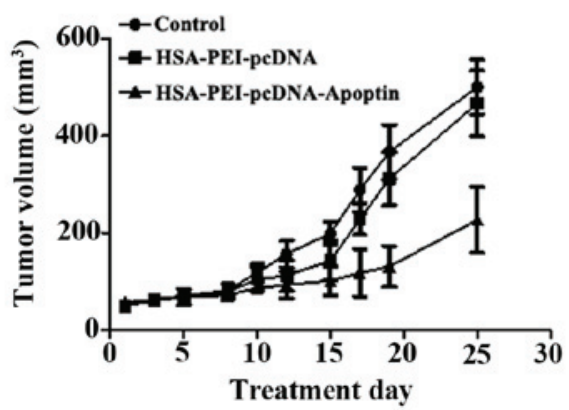

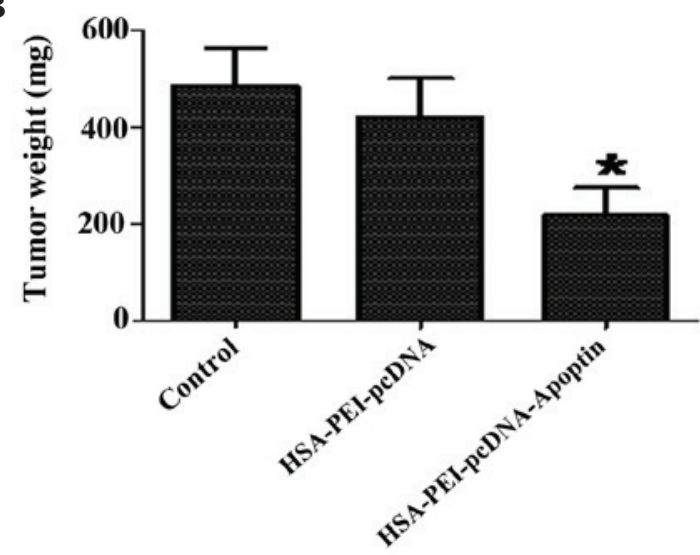

Figure 4. HSA-PEI-pcDNA-Apoptin effectively inhibited tumor growth in vivo. Female nude mice were injected with MCF-7 human breast cancer cells and divided into three groups: HSA-PEI-pcDNA-Apoptin group, HSA-PEI-pcDNA group and the saline (control group). The mice in these groups were injected with the expression vectors or $\mathrm{NaCl}$ once daily for 25 days. (A) The tumor tissue of the female nude mice following sacrifice. (B) Tumor weight was significantly reduced in the mice injected with the HSA-PEI-pcDNA-Apoptin expression vector. ${ }^{*} \mathrm{P}<0.05$ vs. HSA-PEI-pcDNA. (C) Tumor volumes were measured every 3 days during treatment. HSA, human serum albumin; PEI, polyethylenimine; NaCl, sodium chloride.

change (Fig. 3A). MCF-7 cells were positively stained with Annexin V-PE and 7-ADD, and flow cytometric analysis showed that the apoptosis of MCF-7 cells transfected with HSA-PEI-pcDNA-Apoptin was significantly increased from
$9.13 \pm 1.65$ to $27.23 \pm 7.23 \%$ ( $\mathrm{P}=0.013$ vs. control; Fig. $3 \mathrm{~B})$. These results suggest that HSA-PEI-pcDNA-Apoptin has a significant effect on the apoptosis and viability of breast cancer cells. 

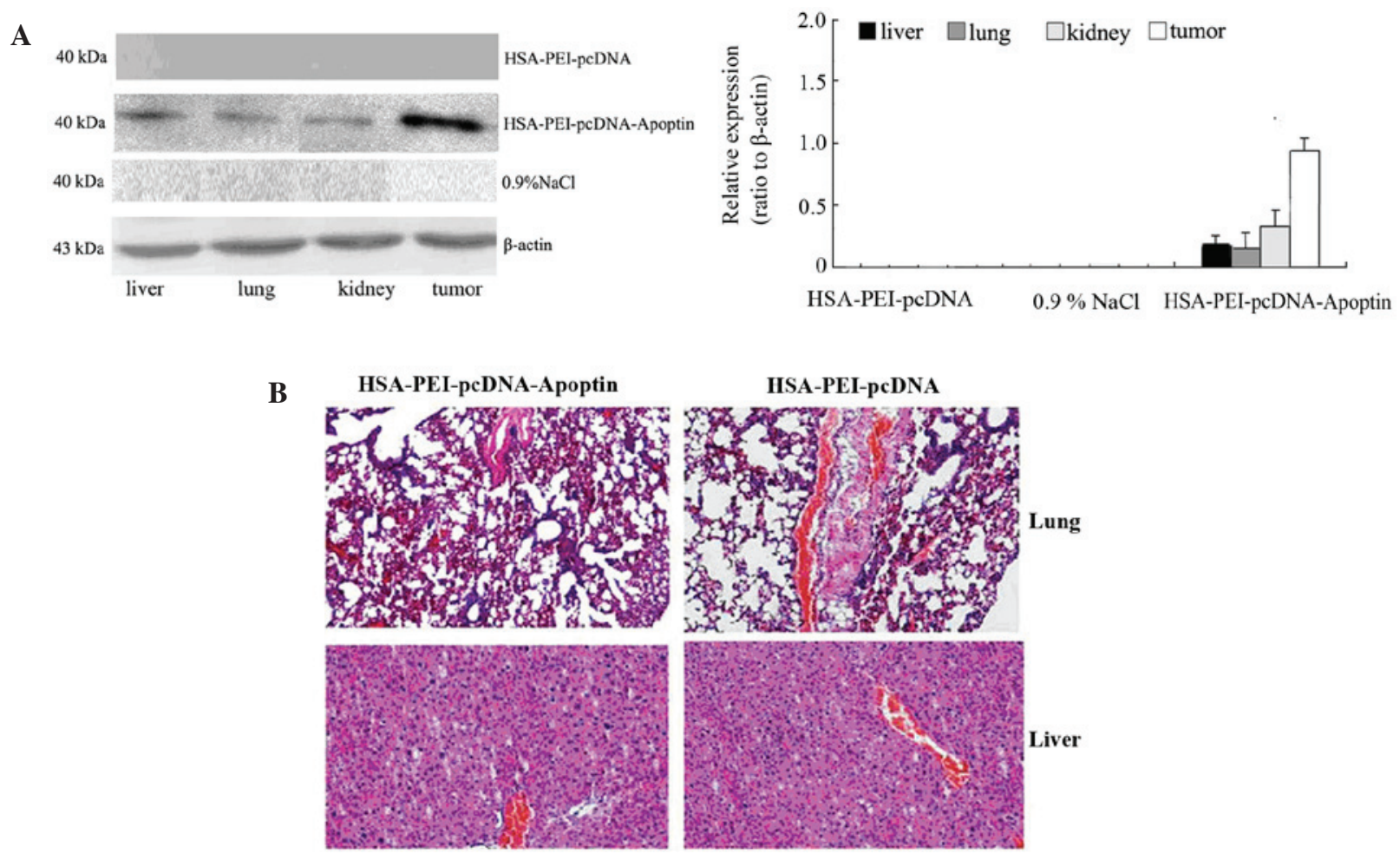

Figure 5. Effect of HSA-PEI-pcDNA-Apoptin on normal and tumor tissues. (A) Apoptin was upregulated in the tumor tissues of the HSA-PEI-pcDNA-Apoptin group, but showed low levels of expression in normal tissues, including the liver, lungs and kidney, as demonstrated by western blotting. Apoptin was rarely expressed in the HSA-PEI-pcDNA group and control group mice. (B) Hematoxylin and eosin staining showed that no overt pathological changes were noted in the lung and liver tissues of mice injected with HSA-PEI-pcDNA-Apoptin (magnification, x200). HSA, human serum albumin; PEI, polyethylenimine; NaCl, sodium chloride.

HSA-PEI-pcDNA-Apoptin effectively inhibits tumor growth in MCF-7 xenografts. To evaluate the therapeutic effects of HSA-PEI-pcDNA-Apoptin in vivo, HSA-PEI-pcDNA-Apoptin, HSA-PEI-pcDNA or saline were injected into the tail veins of BALB/c (nu-nu) athymic nude mice bearing MCF-7 cells once per day for 25 days, and the tumor volumes were measured every 3 days. As is shown in Fig. 4, HSA-PEI-pcDNA-Apoptin markedly inhibited tumor growth, including tumor weight and volume, whereas there were no significant changes in the control group and HSA-PEI-pcDNA group. The tumor weights following sacrifice were significantly reduced in the mice injected with HSA-PEI-pcDNA-Apoptin ( $\mathrm{P}=0.0011$ vs. HSA-PEI-pcDNA).

Expression of apoptin in breast tumor and normal tissues. Western blotting was performed to detect whether apoptin was expressed in the tumor tissue and normal tissues of mice injected with HSA-PEI-pcDNA-Apoptin. As is shown in Fig. 5A, the mice injected with HSA-PEI-pcDNA-Apoptin showed positive apoptin protein expression in the normal tissues (liver, lungs and kidneys) and tumor tissues, although the expression of apoptin was higher in the tumor tissue compared with the normal tissues. Apoptin expression was rarely detected in the mice injected with HSA-PEI-pcDNA or saline (Fig. 5A). In addition, the paraffin-embedded sections of the mice lung and liver tissues were stained with $\mathrm{HE}$, and the tissue morphology was observed under a microscope. As is shown in Fig. 5B, there were no pathological changes in the lung and liver tissues of the mice injected with HSA-PEI-pcDNA-Apoptin or
HSA-PEI-pcDNA, suggesting that apoptin causes no damage to normal tissues.

\section{Discussion}

Efficacy and specificity is an important requirement for successful cancer therapy (12). The present study demonstrated the in vitro and in vivo effects of an HSA-carrying apoptin construct on MCF-7 human breast cancer cells. Notably, this recombinant HSA-PEI-pcDNA-Apoptin construct was able to selectively induce the apoptosis of breast tumor cells.

Apoptin is a protein of $13.6 \mathrm{kDa}$ that was derived from the CAV and is encoded by the VP3 gene (13,14). Apoptin has been shown to selectively induce the apoptosis of a variety of tumor cells, including hepatomas, lymphomas, cholangiocarcinomas, melanomas, and breast, lung, oral and colon carcinomas, while not affecting the normal non-transformed human cells, including primary fibroblasts, smooth muscle cells, T-cells, hepatocytes, hematopoietic stem cells, keratinocytes and endothelial cells (13,15-17). In addition, numerous human tumor cell lines were shown to be susceptible to apoptin $(12,18-20)$, which makes it a promising new tool for cancer gene therapy. However, efficient systems are required to deliver apoptin to cancer cells or to promote the expression of apoptin within these cells. The apoptin gene is suitable for inclusion in technologies such as conditionally replicative viruses or nonviral transduction methods because of its potency and small size; however these novel delivery strategies are yet to be validated (21). HSA may be a good choice for a vector because of its characteristics: 
HSA is a major protein component of blood plasma that has an important function in regulating colloidal osmotic pressure and transporting numerous endogenous compounds, including fatty acids, hormones, toxic metabolites and bile acids (22). Furthermore, HSA selectively binds to various drug molecules, and in doing so alters their pharmacokinetic properties and biological activity $(23,24)$. In a previous study, an antitumor effect was reported in human breast cancer cell lines transfected with a $\lambda$ phage nanobioparticle expressing the apoptin gene (12). This platform allowed the present study to successfully construct an apoptin expression vector that effectively transported apoptin into breast cancer cells. The results presented in this study provide suggested that HSA-mediated apoptin infection was able to reduce the viability and induce the apoptosis of MCF-7 cells. Furthermore, intravenous delivery of the HSA-PEI-pcDNA-Apoptin construct decreased tumor growth in vivo, and resulted in no damage to normal tissues.

At present, cancer therapy includes surgery, chemotherapy, radiotherapy, targeted therapy and immunotherapy. However, these conventional therapeutic methods have unavoidable side effects, and resistance to cancer therapies has been reported for the majority of tumors (25-32). Novel therapeutic approaches that facilitate the selective targeting of cancer cells have emerged in recent years. Furthermore, gene therapy has become a research hot-spot. Gene therapy involving the delivery of apoptin into cancer cells offers unique advantages over current approaches for cancer therapy. Guan et al (18) developed a construct involving the Salmonella typhimurium-mediated delivery of apoptin into human laryngeal cancer cells, and demonstrated that the recombinant was able to induce apoptosis in these cells in vitro and in vivo, without causing significant side effects on normal tissues. van der Eb et al (19) used HepG2 tumor-bearing mice to investigate the in vivo effects of an adenovirus-expressing apoptin, and demonstrated that treatment with apoptin significantly improved the long-term survival of the mice. Other experiments also reported that apoptin is a promising and useful gene for cancer therapy (33-35).

In conclusion, the present study generated a recombinant HSA-PEI-pcDNA construct expressing apoptin, and investigated its antitumor effects in vitro and in vivo. In vitro analyses demonstrated that the HSA-PEI-pcDNA-Apoptin construct resulted in the successful expression of apoptin in MCF-7 cells, and induced the apoptosis of these cells. In vivo experiments showed that the injection of HSA-PEI-pcDNA-Apoptin in nude mice bearing MCF-7 cells significantly suppressed tumor growth, without causing damage to normal tissues. These results indicated that HSA-PEI-pcDNA-Apoptin may be considered a potential therapeutic agent for the treatment of solid tumors, as apoptin was specifically active in malignant cells and its toxicity in normal cells was negligible. However, the mechanism of apoptin-induced cell death has yet to be fully elucidated and should be investigated in further experiments. In addition, further studies are required using breast tumor models to determine the tumor-specific apoptotic effect of the recombinant complex in its actual target environment, as well as its most appropriate application in gene therapy.

\section{Acknowledgements}

The authors would like to thank Professor Chen Huang at Xi'an Jiaotong University for providing the platform to conduct the experiments and for the expert advice. This study was supported by the Natural Science Foundation of Shaanxi Province, China (grant no. S2013JC10894).

\section{References}

1. Xue $\mathrm{H}$, Ni $\mathrm{P}$, Lin $\mathrm{B}, \mathrm{Xu} \mathrm{H}$ and Huang G: X-ray repair cross-complementing group 1 (XRCC1) genetic polymorphisms and gastric cancer risk: A HuGE review and meta-analysis. Am J Epidemiol 173: 363-375, 2011.

2. Jemal A, Siegel R, Ward E, Hao Y, Xu J and Thun MJ: Cancer statistics, 2009. CA Cancer J Clin 59: 225-249, 2009.

3. DeSantis C, Siegel R, Bandi P and Jemal A: Breast cancer statistics, 2011. CA Cancer J Clin 61: 409-418, 2011.

4. Cao W, Wang X and Li JC: Hereditary breast cancer in the Han Chinese population. J Epidemiol 23: 75-84, 2013.

5. Chen WQ, Zeng HM, Zheng RS, Zhang SW and He J: Cancer incidence and mortality in china, 2007. Chin J Cancer Res 24: $1-8,2012$.

6. Gehrig S, Sami H and Ogris M: Gene therapy and imaging in preclinical and clinical oncology: Recent developments in therapy and theranostics. Ther Deliv 5: 1275-1296, 2014.

7. Noteborn MH, Verschueren CA, Zantema A, Koch G and van der Eb AJ: Identification of the promotor region of chicken anemia virus (CAV) containing a novel enhancer-like element. Gene 150: 313-318, 1994.

8. Danen-Van Oorschot AA, Fischer DF, Grimbergen JM, Klein B, Zhuang S, Falkenburg JH, Backendorf C, Quax PH, Van der $\mathrm{Eb} \mathrm{AJ}$ and Noteborn $\mathrm{MH}$ : Apoptin induces apoptosis in human transformed and malignant cells but not in normal cells. Proc Natl Acad Sci USA 94: 5843-5847, 1997.

9. O'Connor TP and Crystal RG: Genetic medicines: Treatment strategies for hereditary disorders. Nat Rev Genet 7: 261-276, 2006.

10. Kobayashi K: Summary of recombinant human serum albumin development. Biologicals 34: 55-59, 2006.

11. Rhaese S, von Briesen H, Rübsamen-Waigmann H, Kreuter J and Langer K: Human serum albumin-polyethylenimine nanoparticles for gene delivery. J Control Release 92: 199-208, 2003.

12. Shoae-Hassani A, Keyhanvar P, Seifalian AM, Mortazavi-Tabatabaei SA, Ghaderi N, Issazadeh K, Amirmozafari N and Verdi J: $\lambda$ Phage nanobioparticle expressing apoptin efficiently suppress human breast carcinoma tumor growth in vivo. PLoS One 8: e79907, 2013

13. Maddika S, Mendoza FJ, Hauff K, Zamzow CR, Paranjothy T and Los M: Cancer-selective therapy of the future: Apoptin and its mechanism of action. Cancer Biol Ther 5: 10-19, 2006.

14. Noteborn MH, Todd D, Verschueren CA, de Gauw HW, Curran WL, Veldkamp S, Douglas AJ, McNulty MS, van der EB AJ and Koch G: A single chicken anemia virus protein induces apoptosis. J Virol 68: 346-351, 1994.

15. Tavassoli M, Guelen L, Luxon BA and Gäken J: Apoptin: Specific killer of tumor cells? Apoptosis 10: 717-724, 2005.

16. Backendorf C, Visser AE, de Boer AG, Zimmerman R, Visser M, Voskamp P, Zhang YH and Noteborn M: Apoptin: Therapeutic potential of an early sensor of carcinogenic transformation. Annu Rev Pharmacol Toxicol 48: 143-169, 2008.

17. Los M, Panigrahi S, Rashedi I, Mandal S, Stetefeld J, Essmann F and Schulze-Osthoff K: Apoptin, a tumor-selective killer. Biochim Biophys Acta 1793: 1335-1342, 2009.

18. Guan GF, Zhao M, Liu LM, Jin CS, Sun K, Zhang DJ, Yu DJ, Cao HW, Lu YQ and Wen LJ: Salmonella typhimurium mediated delivery of apoptin in human laryngeal cancer. Int J Med Sci 10: 1639-1648, 2013.

19. van der Eb MM, Pietersen AM, Speetjens FM, Kuppen PJ, van de Velde CJ, Noteborn MH and Hoeben RC: Gene therapy with apoptin induces regression of xenografted human hepatomas. Cancer Gene Ther 9: 53-61, 2002.

20. Zhuang SM, Shvarts A, van Ormondt H, Jochemsen AG, van $\operatorname{der} \mathrm{Eb} \mathrm{AJ}$ and Noteborn MH: Apoptin, a protein derived from chicken anemia virus, induces p53-independent apoptosis in human osteosarcoma cells. Cancer Res 55: 486-489, 1995.

21. Backendorf C, Visser AE, de Boer AG, Zimmerman R, Visser M, Voskamp P, Zhang YH and Nobetorn M: Apoptin: Therapeutic potential of an early sensor of carcinogenic transformation. Annual review of pharmacology and toxicology 48: 143-69, 2008 . 
22. Peters T Jr: All About Albumin: Biochemistry, Genetics, and Medical Applications. 1st edition. Academic Press, San Diego, CA, 1996.

23. Zhao XN, Liu Y, Niu LY and Zhao CP: Spectroscopic studies on the interaction of bovine serum albumin with surfactants and apigenin Spectrochim Acta A Mol Biomol Spectrosc 94: 357-364, 2012.

24. Abdi K, Nafisi SH, Manouchehri F, Bonsaii M and Khalaj A: Interaction of 5-Fluorouracil and its derivatives with bovine serum albumin. J Photochem Photobiol B 107: 20-26, 2012.

25. Aleman BM, Moser EC, Nuver J, Suter TM, Maraldo MV, Specht L, Vrieling C and Darby SC: Cardiovascular disease after cancer therapy. EJC Suppl 12: 18-28, 2014.

26. Visovsky C: Treatment considerations for the management of patients with hormone receptor-positive metastatic breast cancer. J Adv Pract Oncol 5: 321-330, 2014.

27. Wang MJ: Professor Hope S. Rugo: Reversing resistance and hormone therapy for metastatic breast cancer. Chin Clin Oncol 3: $51,2014$.

28. Jerusalem G, Rorive A and Collignon J: The drug of the month Everolimus (Afinitor) for the treatment of metastatic breast cancer. Rev Med Liege 69: 510-517, 2014 (In French).

29. Bergen E, BerghoffAS, Rudas M, Dubsky P, De Vries C, Sattlberger C, Mader RM, Zagouri F, Sparber C, Fitzal F, et al: Taxanes plus trastuzumab compared to oral vinorelbine plus trastuzumab in HER2-overexpressing metastatic breast cancer. Breast Care (Basel) 9: 344-348, 2014
30. Domschke C and Schuetz F: Side effects of bone-targeted therapies in advanced breast cancer. Breast Care (Basel) 9: 332-336, 2014

31. Greenlee H, Balneaves LG, Carlson LE, Cohen M, Deng G, Hershman D, Mumber M, Perlmutter J, Seely D, Sen A, et al; Society for Integrative Oncology: Clinical practice guidelines on the use of integrative therapies as supportive care in patients treated for breast cancer. J Natl Cancer Inst Monogr 2014: 346-358, 2014.

32. Yoo C, Kim SB, Ahn JH, Kim JE, Jung KH, Gong GY, Son BH Ahn $\mathrm{SH}, \mathrm{Ahn} \mathrm{SD}$, Kim $\mathrm{HH}$, et al: A randomized phase II trial of capecitabine plus vinorelbine followed by docetaxel versus Adriamycin plus cyclophosphamide followed by docetaxel as neoadjuvant chemotherapy for breast cancer. Cancer Res Treat 47: 406-15, 2015.

33. An S, Nam K, Choi S, Bai CZ, Lee Y and Park JS: Nonviral gene therapy in vivo with PAM-RG4/apoptin as a potential brain tumor therapeutic. Int J Nanomedicine 8: 821-834, 2013.

34. Liu L, Wu W, Zhu G, Liu L, Guan G, Li X, Jin N and Chi B: Therapeutic efficacy of an hTERT promoter-driven oncolytic adenovirus that expresses apoptin in gastric carcinoma. Int $\mathrm{J}$ Mol Med 30: 747-754, 2012.

35. Pan Y, Fang L, Fan H, Luo R, Zhao Q, Chen H and Xiao S: Antitumor effects of a recombinant pseudotype baculovirus expressing Apoptin in vitro and in vivo. Int J Cancer 126: 2741-2751, 2010. 